\title{
Evolution of Visual Evoked Potentials in Optic Neuritis
}

\author{
Irvin H. Heinrichs and Donald R. McLean
}

\begin{abstract}
The visual evoked potential (VEP) latency was either abnormally prolonged or absent in the involved eye of 47 patients with optic neuritis. Twenty-two of these patients with known multiple sclerosis (MS), had similar abnormalities to 25 patients with no clinical evidence of MS. Follow-up clinical assessment and VEP were done 10 to 42 (mean 22) months later in 34 patients. In 15 of 34 patients with no VEP from the involved eye during initial examination, 6 returned to normal, 8 had prolonged latencies and 1 still had no response at follow up. Of 19 patients who initially had prolonged latencies in the involved eye, 6 returned to normal, 11 had prolonged latencies and 2 had no response at follow up. The VEP is helpful in confirming the diagnosis of ON. The examination must be performed when the patient is symptomatic or soon thereafter as $35 \%$ of our patients with an abnormal initial VEP had a normal VEP at follow up. This normalization was not related to the severity of the initial VEP abnormality.
\end{abstract}

RÉSUMÉ: Evolution des potentiels évoqués visuels au cours de la névrite optique La période de latence des potentiels évoqués visuels (PEV) était soit prolongée de façon anormale ou absente dans l'oeil atteint de névrite optique chez 47 patients. Vingt-deux des patients ayant une sclérose en plaques (SEP) connue avaient des anomalies semblables à celles de 25 patients sans évidence clinique de SEP. Une évaluation clinique subséquente ainsi que des PEV ont été faits 10 à 42 mois (moyenne 22) plus tard chez 34 patients. Des 15 patients sur 34 sans PEV provenant de l'oeil atteint lors de l'examen initial, 6 étaient revenus à la normale, 8 avaient des temps de latence prolongés et 1 n'avait toujours pas de réponse lors de cet examen. Des 19 patients qui avaient initialement des temps de latence prolongés dans l'oeil atteint, 6 étaient revenus à la normale, 11 avaient des temps de latence prolongés et 2 n'avaient pas de réponse lors de l'examen de contrôle. Les PEV sont utiles pour confirmer le diagnostic de névrite optique. L'examen doit être fait quand le patient est symptomatique ou tôt par la suite car $35 \%$ de nos patients qui avaient des PEV anormaux à l'examen initial avaient des PEV normaux à l'examen de contrôle. Cette normalisation n'était pas reliée à la sévérité des anomalies des PEV à l'examen initial.

Can.J. Neurol. Sci. 1988; 15:394-396

The rate of abnormality in the visual evoked potential (VEP) following optic neuritis (ON) is reported to range from being abnormal in all ${ }^{1}$ patients to being abnormal in $83 \%{ }^{2}$ of patients. Similarly the VEP is reported to rarely return to normal $1,3,4,5,6$ or normalize in $35 \%$ of patients. 7,8 This paper reports the VEP in 47 patients examined during their initial phase of $\mathrm{ON}$ and in 34 patients re-examined 10-42 months later. We were particularly interested in whether the evolution of the VEP abnormalities differed in patients with MS and whether the evolution of the VEP related to the severity of the initial abnormality.

\section{METHOD}

Forty-seven patients with ON who had VEP testing done within 3 months of disease onset in a previously unaffected eye were identified from University of Alberta Hospital records and Evoked Reponses Laboratory files. All patients had been examined by a staff ophthalmologist and neurologist. The diagnosis of ON was based on the presence of retro-orbital pain worsened by eye movement, blurred or reduced vision, scotoma, color desaturation especially to red, afferent pupil defect (MarcusGunn pupil) and normal fundoscopic examination. No systemic disease was present to explain the visual loss. Cerebrospinal fluid examination was done in most patients and double dose delayed augmented computed tomographic scanning was performed in some patients.

The patient was designated as having M.S. if they satisfied the criteria for probably and definite according to the classification of Rose et al. ${ }^{9}$ A patient with only optic neuritis is categorized as possible in this classification.

We attempted to recall all patients for repeat VEP testing and 34 patients complied. Their medical records subsequent to the ON were reviewed and all the patients were interviewed and examined by I.H., looking for evidence of MS.

\section{Testing Technique}

The patients were seated in a dimly lit room and instructed to fixate on a small dot centered on the Nicolet 1006 stimulator 
screen, located $1.0 \mathrm{~m}$ from the eye while a black and white checkerboard pattern reversal stimulus was presented at a rate of $0.94 \mathrm{~Hz}$. Eyes were examined independently. The checkerboard square subtended a visual angle of $2^{\circ}$, and the whole screen $12.3^{\circ}$ vertically and $15.9^{\circ}$ horizontally.

The VEP was recorded using tin electrodes, secured with collodion, and filled with conduction jelly. Impedance was less than $10 \mathrm{~K}$ ohm. Bandpass was $1 \mathrm{~Hz}$ to $30 \mathrm{~Hz}$ and recording montage $\mathrm{Oz}-\mathrm{Cz}$, (International 10-20 System). The electrodes were connected to a Nicolet HGA-100A amplifier and one hundred responses were averaged, using a Nicolet CA-1000 Clinical Averager. The VEP was obtained at least twice in each eye, to ensure replication, displayed on an oscilloscope for latency measurement, and then written out with an X-Y plotter. Latency was measured at the peak of the response. Control values were obtained by examining medical students, nurses, technicians, etc. who had no history or signs of neurological disease. Forty subjects (14 males, 26 females) age 19 to 64 (mean 34.4) were examined.

The normal VEP latency in our laboratory is less than 116 msec. (mean $101 \mathrm{msec}$. +3 S.D.). An inter-eye latency difference greater than $6 \mathrm{msec}$. is considered abnormal, even if the longer latency is less than $116 \mathrm{msec}$. A VEP was deemed absent, if no reproducible response appeared after 3 trials.

\section{RESULTS}

\section{A) Initial Examination}

Forty-seven patients fulfilled our criteria for inclusion in the study. The VEP was measured an average of 3.5 weeks (range 1-13 weeks) after the onset of the ON. All the patients had an abnormal VEP in the involved eye.

Table 1 summarizes the VEP results in these 47 patients. Twenty-two patients were diagnosed MS at the time of, or prior

\section{Table 1: Initial VEP in 47 Patients with On}

\begin{tabular}{lcccc}
\hline \hline & $\begin{array}{c}\text { No } \\
\text { Response }\end{array}$ & $\begin{array}{c}\text { Measureable } \\
\text { Response }\end{array}$ & $\begin{array}{c}\text { Range } \\
\text { msec. }\end{array}$ & $\begin{array}{l}\text { Mean } \\
\text { msec. }\end{array}$ \\
\hline $\begin{array}{l}\text { Non MS } \\
25 \text { patients }\end{array}$ & $8(32 \%)$ & $17(68 \%)$ & $120-188$ & 136 \\
\hline $\begin{array}{l}\text { MS } \\
22 \text { patients }\end{array}$ & $10(45 \%)$ & $12(55 \%)$ & $110-181$ & 138 \\
\hline
\end{tabular}

Table I - There is no statistical difference in the responses or laten$c y$ between the non-MS and MS group. (Fisher Exact Test: $p>26$ ) to, the onset of the ON. Twenty-five patients did not have clinical evidence of MS. There was no statistical difference in the mean latency of the measurable responses in these two groups. The proportion of absent responses was not statistically different.

\section{B) Follow-up Examination}

In 34 patients who returned for follow-up, the original diagnosis was $M S$ in 18, and ON alone in 16. At follow-up, 5 patients in the latter group had acquired additional neurological deficits, and were diagnosed as having MS. The elapsed time from the initial symptoms of ON to follow-up averaged 22 months (range 10-42 months).

The 34 patients were divided into two groups for analysis. Group 1 was originally or at follow-up diagnosed as MS. Group 2 had $\mathrm{ON}$ alone, with no additional neurological signs or symptoms to allow a diagnosis of MS.

It should be noted that during a mean follow-up period of 22 months only $50 \%$ of patients destined to develop MS will acquire signs or symptoms to diagnose this progression. $11,12.13$ Consequently there are several patients in group 2 who are destined to enter group 1 eventually and this confounds statistical analysis.

The VEP responses are summarized in Table 2. Analysis by Fishers Exact Text showed no significant difference either in the proportion of absent responses, or in the mean VEP latency, between the 2 groups, either initially or at follow-up.

In 12 of 34 patients (35\%) the follow-up VEP had returned to normal. These 12 patients were proportionately distributed between the 2 groups.

In 15 of 34 patients (44\%) with no response from the involved eye during the initial examination, 6 returned to normal, 8 had prolonged latency and I still had no response at follow up. Of 19 patients with prolonged latency in the involved eye at initial examination, 6 returned to normal, 11 had prolonged latencies and 2 showed no response at follow up.

The initial VEP testing was done an average of 3 weeks (range 1-13 weeks) after onset of $\mathrm{ON}$ in 15 patients with an absent response in the affected eye, and an average of 4 weeks (range 1-9 weeks) after onset of the $\mathrm{ON}$ in 19 patients with a measurable response in the affected eye.

\section{Discussion}

Similar to previous reports ${ }^{1}$ all our patients with $\mathrm{ON}$ initially had an abnormal VEP in the affected eye. Others have reported some patients with $\mathrm{ON}$ who have a normal VEP latency ${ }^{2}$ but it

Table 2: Initial and Follow-up VEP in the Involved Eye of 34 Patients with ON

\begin{tabular}{|c|c|c|c|c|c|c|c|c|}
\hline & \multicolumn{4}{|c|}{ INITIAL VEP } & \multicolumn{4}{|c|}{ FOLLOW-UP VEP } \\
\hline & $\begin{array}{c}\text { No } \\
\text { Response }\end{array}$ & $\begin{array}{c}\text { Measureable } \\
\text { Response }\end{array}$ & $\begin{array}{l}\text { Range } \\
\text { msec. }\end{array}$ & $\begin{array}{l}\text { Mean } \\
\text { msec. }\end{array}$ & $\begin{array}{c}\text { No } \\
\text { Response }\end{array}$ & $\begin{array}{l}\text { Measureable } \\
\text { Response }\end{array}$ & $\begin{array}{l}\text { Range } \\
\text { msec. }\end{array}$ & $\begin{array}{l}\text { Mean } \\
\text { msec. }\end{array}$ \\
\hline GROUP $1 \quad(\mathrm{~N}=23)$ & $11(48 \%)$ & $12(52 \%)$ & $110-154$ & 133 & $1(4 \%)$ & $22(96 \%)$ & $98-163$ & 122 \\
\hline GROUP $2 \quad(N=11)$ & $4(36 \%)$ & $7(64 \%)$ & $124-188$ & 143 & $2(18 \%)$ & $9(82 \%)$ & $100-134$ & 123 \\
\hline
\end{tabular}

Table 2 - Group I had probable or definite MS at the time of initial examination or at follow up. Group 2 had ON alone initially and at follow' up. There is no significant difference between Group I and Group 2 in terms of presence or absence of response and latency at the initial examination (Fischer Exact test $P>40$ ) and at follow up (Fischer Exact test $P>.24$ ). 
is unclear how much time had elapsed between the onset of ON and the VEP testing. If the VEP examination is delayed, that stage of the illness with an abnormal VEP may be missed.

The VEP was initially absent in 15 of 34 follow-up patients (44\%). That this very abnormal response reflects the stage of their illness is evident at follow-up, when 14 of 15 initially absent VEP returned. Wildeberg and Van Lith' noted that 6 of 12 patients with acute $\mathrm{ON}$ had an absent response in the affected eye; at follow up, only 1 patient had an absent response.

In 12 of our 34 patients $(35 \%)$ at follow-up, the VEP had become normal. While some studies have reported similar results 7,8 others have found that an abnormal VEP in ON rarely returns to normal. $1,2,3,4,5,6$ Our stimulating technique differs from that used by other authors. The stimulation square size in our study was $2^{\circ}$ which is larger than in other studies. Kirkham and Coupland 8 found that only $40 \%$ of the patients with ON had an abnormal VEP, and they used $12^{\circ}$ arc flash stimulus. However the testing was delayed up to 5 years in some patients which probably accounts for the low yield of abnormal responses. Mallecourt et al ${ }^{5}$ compared the use of $8^{\circ}$ arc squares and $20^{\circ}$ arc squares, and found a significant prolongation in VEP latency when the small stimulus size was used. It was their opinion that prolonged VEP latencies never revert to normal, and that all apparent VEP "normalizations" can be explained by using arc squares that are too large.

We attempted to alter the VEP latency by reducing the stimulus size in a few patients with normalized VEP and were unsuccessful.

One other variable is the rate of pattern reversal, or flash stimulation. Those studies which found a low rate of VEP normalization $1,4.5$ used frequencies of 2.2 to $8.0 \mathrm{~Hz}$, while other studies $^{8,10}$ and ours, which reported a higher rate of VEP normalization, used frequencies of 0.94 to $1.0 \mathrm{~Hz}$. It is possible that a higher rate of pattern reversal makes the test more sensitive, but this variable has not yet been formally investigated.

Recent articles ${ }^{14,15}$ have questioned the cost-effectiveness and redundancy of evoked response testing in clinical medicine. Visual evoked responses were always abnormal in our patients with acute O.N. and certainly corroborated a fairly obvious clinical diagnosis. This "lab test" confirmation was probably reassuring to the attending physician and patient but served no other function as the results did not alter treatment, offer prognosis nor predict the development of M.S. Visual evoked response testing is much more useful in patients with suspected M.S. who have no visual symptoms or signs. In these cases, a "second" silent lesion of the optic nerve may be identified which facilitates the diagnosis.
VEP is an accurate test which corroborates the diagnosis of ON. The examination must be performed when the patient is symptomatic or soon thereafter as $35 \%$ of our patients with an abnormal initial VEP had normal responses at follow up.

\section{ACKNOWLEDGEMENTS}

The authors express their thanks to H. Campbell for technical assistance, and to Drs. K. Warren and D. Carroll for access to the files of the MS Clinic. Supported by funds received from the Medical Services Research Foundation of Alberta.

\section{REFERENCES}

1. Wildeberg HGH, Van Lith GHM. Color vision and visually evoked responses (VEP) in the recovery period of optic neuritis. Mod Probl Ophthalmol 1975; 17: 320-324.

2. Matthews WB, Small DG, Small M, et al. Pattern reversal evoked visual potential in the diagnosis of multiple sclerosis. J Neurol Neurosurg Psychiatry 1977; 40: 1009-1014.

3. Halliday AM, McDonald WI, Mushin J. Delayed visual evoked response in optic neuritis. Lancet 1972; 1: 982-985.

4. Kjaer M. Visual evoked potentials in normal subjects and patients with multible sclerosis. Acta Neurol Scand 1980; 62: 1-13.

5. Mallecourt J, Chain F, Leblanc M, et al. Analysis of visual evoked response in multiple sclerosis. Biomedicine 1980; 32: 210-216.

6. Chiappa $\mathrm{KH}$, Ropper AM. Evoked potentials in clinical medicine. N Engl J Med 1982; 306: 1140-1150.

7. Bynke H, Rosen I, Sandberg-Woolheim M. Correlation of visual evoked potentials, ophthalmological and neurological findings after unilateral optic neuritis. Acta Ophthalmol 1980; 58, 5: 673687.

8. Kirkham TH, Coupland SG. Multiple regression analysis of diagnostic predictors in optic nerve disease. Can J Neurol Sci 1981; 8: 67-72.

9. Rose AS, Ellison GW, Myers LW. Criteria for the clinical diagnosis of M.S. Neurology 1976; 26: 20-22.

10. McDonald WI, Halliday AM. Diagnosis and classification of multiple sclerosis. Br Med Bull 1977; 33: 4-8.

11. Compston DAS, Batchelor JR, Earl CJ, et al. Factors influencing the risk of multiple sclerosis developing in patients with optic neuritis. Brain 1978; 101: 495-511.

12. McAlpine D, Compston N. Some aspects of the natural history of disseminated sclerosis. Q J Med 1952; 21 : 135-167.

13. Cohen MM, Lessell S, Wolf PA. A prospective study of the risk of developing multiple sclerosis in uncomplicated optic neuritis. Neurology 1979; 29: 208-213.

14. Chiappa KH, Young RR. Evoked responses. Overused, Underused or Misused? Arch Neurol 1985; 42: 76-77.

15. Eisen A, Cracco RQ. Overuse of evoked potentials: Caution Neurology 1983; 33: 618-621. 